\title{
Inexpensive Sand Filters for Drip Irrigation Systems
}

\author{
B.W. Roberts ${ }^{1}$ and \\ C.W. O Hern ${ }^{2}$
}

Additional index words. water, trickle, vegetable

Summary. Solid particles in water such as sand, silt, clay, or organic debris can clog drip irrigation systems. Filters that remove these particles from the water are necessary, but expensive, for small-scale or part-time farmers. A falter that is functionally similar to commercial units can be built from a steel barrel and common plumbing supplies for about $\$ 100$. Components and instructions to build such a falter are presented here.

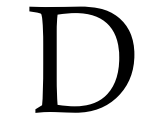

rip irrigation systems are used extensively by commercial vegetable producers. There are numerous advantages offered by drip irrigation systems over conventional overhead irrigation systems. Drip irrigation systems permit precise water placement for efficient use of water. There is less chance of foliar disease development from wet foliage because the water from drip irrigation is applied to the soil and not to the plant. Drip irrigation requires less energy to operate than conventional systems because a pressure of 8 to $10 \mathrm{psi}$ ( 55 to $69 \mathrm{kPa}$ ) is sufficient to operate drip irrigation systems. This pressure can be obtained withless-expensive, lowerpressure pumps than are needed for typical overhead irrigation systems. Drip irrigation can be used with water sources with low recharge rates. Some

Wes Watkins Agricultural Research \& Extension Center, Department of Horticulture and Landscape Architecture, Oklahoma State University, Box 128, Lane, OK 74555.

${ }^{1}$ Associate Professor.

${ }^{2}$ Agricultural Research Technician.

Journal Article No. 55897 of the Agricultural Experiment Station, Oklahoma State Univ., Stillwater. This research was supported in part by CSRS-Special Grant 90-34146-5023. 
wells are sufficient for drip irrigation that do not supply sufficient flow rates for overhead irrigation systems.

There are also disadvantages with drip irrigation systems. Individual emitter openings in the drip line are small, and often emit from 0.1 to $0.2 \mathrm{gal} / \mathrm{h}$ (0.38 to 0.76 liters $/ \mathrm{h})$. The small emitters can become clogged easily with either organic particles such as algae, weeds, and leaves, or with inorganic solid particles such as sand, silt, and clay. Water from many farm ponds and some well or municipal waters contains sufficient solid particles to clog the drip emitters. Such water is not suitable for drip irrigation unless filters are used to remove the solid particles.

Various filters have been designed and marketed that will remove most solid particles from the water. If emitters in drip lines are to be kept open, filters should remove all particles $>0.003$ inches $(70 \mathrm{pm})$. Number 20 crushed silica sand, which yields an effective 200 -mesh filter bed, is recommended in such filters (T-Systems Corp. ). Commercial-sized filters are now available that will filter water for several acres at one time, but may cost well in excess of $\$ 1000$. Filters designed for swimming pool filtration function well if no more than 1 acre is irrigated at a time, but even these filters cost from $\$ 500$ to $\$ 1000$.

Small-scale vegetable producers often need to irrigate an acre or less at one time. When water is limited in supply or is expensive to purchase, drip irrigation is an ideal choice for such farmers. However, the cost of commercial sand filters, when added to the cost of the drip line and pumping hardware, increases the total cost of drip irrigation systems to the point that it is prohibitive to growers with limited capital.

If drip irrigation systems are to be accessible to small-scale growers, filtration systems need to be as inexpensive as possible. The filter should be constructed easily from readily available materials. We have designed and constructed such a filter from standard hardware and plumbing materials. The filter system works well for small-scale operations that require low flow rates of water. The basic components are a 55-gal (208-liter) steel barrel, schedule 40 PVC pipe and fittings, sand, and gravel. A basic functional filter can be built for about $\$ 50$, and the model with the options described here can be built for about $\$ 100$.

The filter described here is not a high-pressure device, and is not intended to handle pressures $>10$ psi $(69$ $\mathrm{kPa}$ ). Excessively high pressures will result in leakage, and possible rupturing of the barrel. For safety purposes, a main cutoff valve and pressure regulator should be installed before the filter if there is a possibility of highpressure water entering the filter.

The filter operates by allowing water to pass through a bed of sand, with the sand trapping solid particles from the water. The main part of the filter, a steel barrel, is placed upright on a support structure made from concrete, stone, steel, or decay-resistant wood products. The support structure with the filter can be either stationary or mobile, depending on the intended use of the filter. The structure should be designed to support the bottom (end) of the barrel, while allowing the water inlet and drain lines access to the barrel. The steel barrel is placed upright on the supports, gravel is placed in the bottom of the barrel, and sand is placed on top of the gravel. Water enters the bottom of the barrel through a PVC pipe manifold, which is embed- ded in the gravel layer. As water accumulates in the barrel and rises toward the top, it must pass through the layer of sand with numerous pores and channels that trap solid particles while allowing water to pass upward. The filtered water then exits the barrel at the top.

Because the water enters from the bottom, and exits at the top of the barrel, there is little risk of sand leaving the barrel with the filtered water. There is a chance that low-density, organic materials originally found in the sand could float to the top of the barrel and exit with the filtered water. The risk of contamination from these floating materials is greatest the first time that water is passed through the filter. To minimize the risk of these contaminants entering the drip irrigation lines, the first few gallons of water should be purged from the barrel before connection is made to the drip lines, or a secondary filter can be inserted into the outlet line.

The plumbing parts in the filter are made primarily from 1 -inch $(3.8-\mathrm{cm})$ schedule 40 PVC pipe. A larger-diameter pipe could be used, with less flow restriction through the system. However, because all fittings

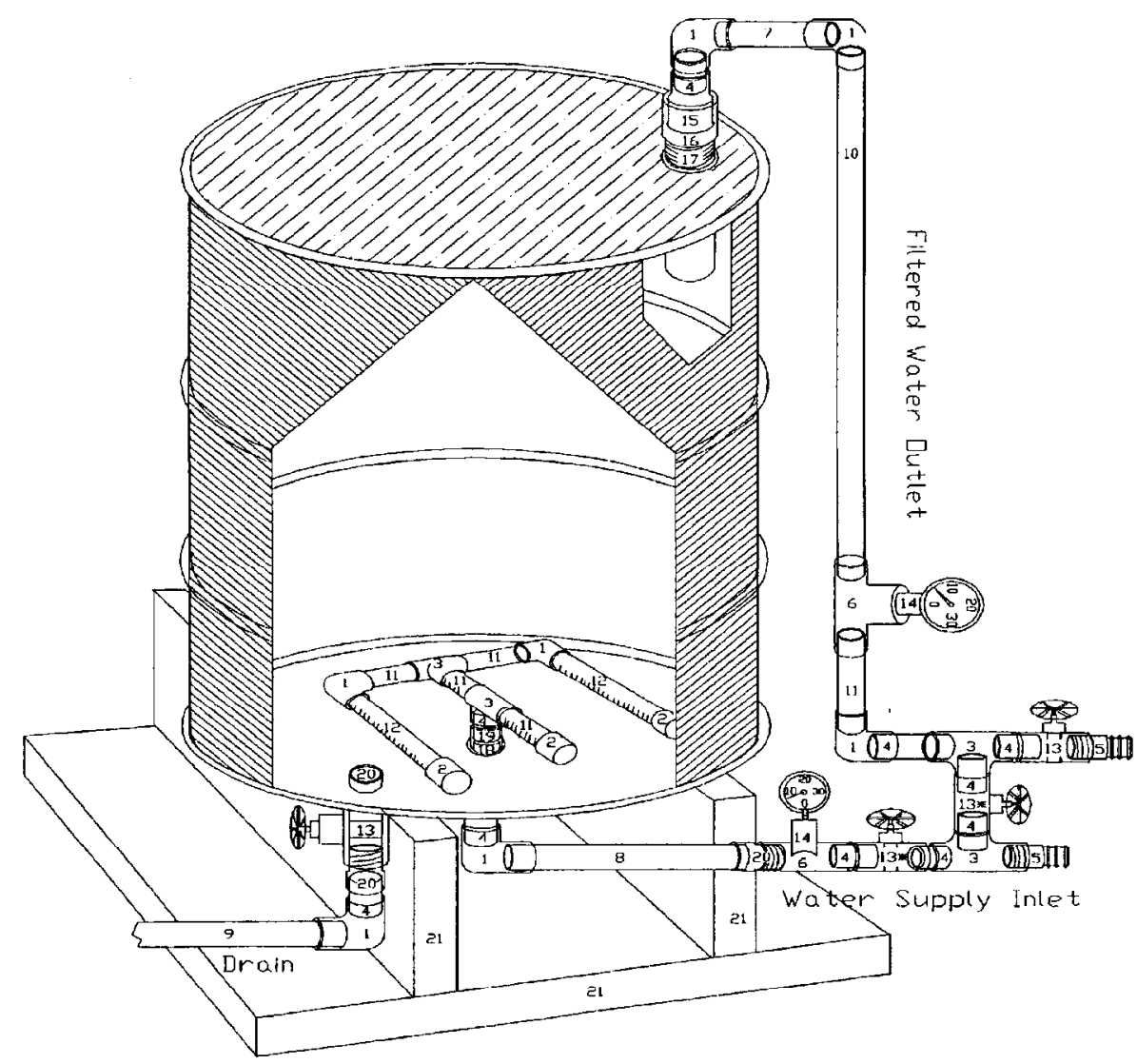

Fig. 1. Diagram of filter with component parts. 
Table 1. List of parts needed to complete the filter assembly shown in Fig. 1.

\begin{tabular}{|c|c|c|c|c|}
\hline Part no. & Description & Diameter & Length & Quanitity \\
\hline 1 & Elbow & $1 / 21$ & $-\cdots$ & 7 \\
\hline 2 & Cap & $1 \frac{1}{2}$ & -- & 3 \\
\hline 3 & Tee & $1 \frac{1}{2}$ & --- & 4 \\
\hline 4 & Pipe & $1^{1} /{ }^{\prime \prime}$ & $2^{\prime \prime}$ & 10 \\
\hline 5 & Male thread $\times$ poly slip coupling & $1 \frac{1}{2}$ & --- & 2 \\
\hline 6 & Tee (with $3 / 8$ "female side thread) & $1 \frac{1,11}{2}$ & -- & 2 \\
\hline 7 & Pipe & $1 \frac{1}{2}$ & $12^{\prime \prime}$ & 1 \\
\hline 8 & Pipe & $1 \frac{1}{2}$ & $18^{\prime \prime}$ & 1 \\
\hline 9 & Pipe & $1 \frac{1}{2}$ & $>6^{\prime \prime}$ & 1 \\
\hline 10 & Pipe & $1 \frac{1}{2}$ & $33^{\prime \prime}$ & 1 \\
\hline 11 & Pipe & $11^{1}$ & $6^{\prime \prime}$ & 5 \\
\hline 12 & Pipe & $1 / 2$ & $13^{\prime \prime}$ & 2 \\
\hline 13 & Cut-off valve & $11^{1}$ & --- & 4 \\
\hline 14 & Pressure gauge & $1{ }^{1} / 2$ & -- & 2 \\
\hline 15 & $\operatorname{Reducer}\left(2^{\prime \prime} \times 1^{1} / 2\right)$ & $-\cdots$ & --- & 1 \\
\hline 16 & Female slip $\times$ female thread coupling & $2^{\prime \prime}$ & $-\cdots$ & 1 \\
\hline 17 & Threaded nipple & $2^{\prime \prime}$ & $5^{\prime \prime}$ & 1 \\
\hline 18 & Threaded nipple & $1 \frac{1}{2}$ & $2^{\prime \prime}$ & 1 \\
\hline 19 & Female slip $\times$ female thread coupling & $1 \frac{1}{2}$ & --- & 2 \\
\hline 20 & Female slip $\times$ male thread coupling & $1 \frac{1}{2}$ & --- & 3 \\
\hline 21 & $\begin{array}{l}\text { Support frame (variable, made from steel, } \\
\text { concrete, decay-resistant wood, etc.) }\end{array}$ & & & \\
\hline
\end{tabular}

and valves would also need to be increased in size, there would be an increase in construction cost. A smallerdiameter pipe would be fictional if lower flow rates were acceptable.

The 1-inch $(3.8-\mathrm{cm})$ pipe is inserted into the bottom of the barrel (Fig. 1). The hole should have a diameter equivalent to the outside diameter of the PVC pipe. A threaded nipple (part \#18, Table 1; Fig. 1) extends through the hole in the bottom of the barrel, and female-threaded couplings (part \#19, Table 1; Fig. 1) are tightened securely onto both ends of the nipple, so that the bottom of the barrel is trapped between the two couplings. Waterproof gasket sealant should be used where the threaded couplings make contact with the barrel.

The remainder of the water delivery system is constructed according to the diagram in Fig. 1. The two rows of slots in each parallel section of the pipe are cut with a radial saw. The slots in each row are 1 inch $(2.5 \mathrm{~cm})$ apart, and each slot is 1 inch $(2.5 \mathrm{~cm})$ long and $1 /{ }_{8}$ inch $(0.3 \mathrm{~cm})$ wide (a saw-blade width). The rows of slots should be at the 4:00 to 5:00 o clock and 7:00 to 8:00 o clock positions on the horizontal pipe. By positioning the rows of slots at this angle, the incoming flow of water is directed downward, away from the sand. This will minimize the chance of the sand being stirred or rearranged by the force of the water, and will increase the filtering efficiency of the sand.

Gravel $[1 / 4$ to $1 / 2$ inch $(0.6$ to $1.3 \mathrm{~cm})$ in diameter] is added to the bottom of the barrel in an amount sufficient to cover the water delivery tubes by 2 inches $(5 \mathrm{~cm})$. The gravel stabilizes the water delivery tubes and supports the weight of sand that will be placed on top of the gravel. Gravel is preferable to sand because the large pores will allow relatively unrestricted flow of water from the tubes. A wire screen (50-mesh) is placed on top of the gravel, and sand [ $1 \mathrm{ft}(0.3 \mathrm{~m})$ deep] is placed on top of the screen. The screen prevents sand from settling into the gravel.

The barrel could be one of several sizes, although a 55-gal (208-liter) capacity barrel works well. It is very important that the barrel be clean and not contain toxic residues. Barrels that have contained concentrated fruit juices or other food products are suitable, while barrels that previously have contained toxic chemicals should never be used. The barrel is not recommended at pressures above 10 psi $(69 \mathrm{kPa})$. Excessively high pressures will result in leakage, and possible rupturing of the barrel.

The barrel should have a removable top with a gasket and ring that can be fastened securely. Most 55-gal (208-liter) barrels will have a 2-inch (5-cm) diameter hole in the top lid. This hole can be used for installing the pipe for the water outlet. The fittings connected to the top of the barrel are 2 inches $(5 \mathrm{~cm})$ in diameter, while all other fittings are 1 inch $(3.8 \mathrm{~cm})$ in diameter. The bottom of the water outlet (part \#17) should extend 4 inches $(10 \mathrm{~cm})$ below the top lid of the barrel. This ensures that debris floating on top of the water will rise to the top of the barrel and will not exit through the water outlet. As a precaution, a screen filter mounted in the water outlet outside of the barrel will serve as a backup to trap any remaining debris.

As debris accumulates in the sand with normal use, water flow will be restricted. Two pressure gauges (part \#14) are installed in the system, one before and one after the barrel filter. As the accumulated debris restricts water flow, the pressure on the outlet side will decrease. By observing pressure differences at the two gauges, the user can determine when the system should be back-flushed to remove sediments. The quantity of water that can be filtered before back-flushing is required will depend on the purity of the water. Because the flow of water during normal operations is from bottom to top, impurities in the water will be collected in the bottom of the barrel. These impurities can then be washed from the bottom of the barrel through the drain (part \#9) during back-flushing. In order to determine the effectiveness of the back-flushing operation, a series of four tests was conducted to determine the pressure differential across the filter before and after back-flushing. With each test, surface pond water with a variable sediment content [ 0.2 to $0.4 \mathrm{~g}$ of sediment per 0.26 gal (1 liter)] was directed through the filter until the outlet pressure was substantially decreased. The water inlet pressure was maintained at $10 \mathrm{psi}(69 \mathrm{kPa})$. When the outlet pressure became substantially reduced, the filter was backflushed with 100 gal (378.4 liters) of water. After each back-flushing, the pressure on the outlet side returned to the original reading of 8 psi $(55 \mathrm{kPa})$, indicating that the back-flushing operation was successful (Table 2).

It is possible that the back-flushing process may not remove all of the contaminants that become lodged in 
Table 2. Inlet and outlet water pressure after water was either filtered or back-flushed through the filter.

\begin{tabular}{|c|c|c|c|c|c|c|c|}
\hline \multicolumn{2}{|c|}{ Water filtered } & \multicolumn{2}{|c|}{ Water back-flushed } & \multicolumn{2}{|c|}{ Inlet pressure } & \multicolumn{2}{|c|}{ Outlet pressure } \\
\hline (gal) & (liters) & (gal) & (liters) & $\overline{(p s i)}$ & $\overline{(\mathrm{kPa})}$ & (psi) & $(\mathrm{kPa})$ \\
\hline 0 & 0 & 0 & $\mathbf{0}$ & 10 & 69 & 8 & 55 \\
\hline 2731 & 10,334 & 0 & 0 & 10 & 69 & 4 & 28 \\
\hline 0 & 0 & 100 & 378 & 10 & 69 & 8 & 55 \\
\hline 1789 & 6,770 & 0 & 0 & 10 & 69 & 2 & 14 \\
\hline 0 & 0 & 92 & 348 & 10 & 69 & 8 & 55 \\
\hline 2895 & 10,995 & 0 & 0 & 10 & 69 & 4 & 28 \\
\hline 0 & 0 & 101 & 382 & 10 & 69 & 8 & 55 \\
\hline 3607 & 13,649 & 0 & 0 & 10 & 69 & 2 & 14 \\
\hline 0 & 0 & 100 & 378 & 10 & 69 & 8 & 55 \\
\hline 4410 & 16,687 & 0 & 0 & 10 & 69 & 6 & 41 \\
\hline
\end{tabular}

the sand. With extended use, depending on the relative purity of the irrigation water supply, the pressure loss through the filter could be increased. If, after extended use, back-flushing does not allow sufficient water flow through the filter, the sand can be replaced.

A pair of cut-off valves (part \#13, identified on Fig. 1 as $13^{*}$ ) allows the flow of water to be routed from the bottom to the top of the barrel for normal filtration, or in reverse order to flush and back-wash the system. When back-flushing, the drain at the bottom of the barrel is opened to expel the collected sediments. Many commercially available sand filtration systems allow back-flushing with clean water by connecting two similar filters in such away that the clean water from one filter is used to back-flush the second filter. This same approach can be used with the filtration system described here, if two filters instead of one are constructed. However, the main reason for building this filter system is to limit the capital investment, which would be doubled if two filters were constructed. An alternative is to back-flush with unfiltered water, and then to purge the system of any unfiltered water by allowing the first several gallons of water to be flushed through the system before the filter is reconnected to the drip irrigation lines. The relative purity of the unfiltered water should be considered in determining the best method for back-flushing.

If the filter will be used with any fertilizer or chemical injection accessories, a backflow prevention valve must be added to prevent possible contamination of the water supply. If there is a possibility that excessively high water pressures could be applied to the filter, a pressure relief valve should be added.

Accessories shown here include extended drain lines (part \#9), pressure gauges (part \#14), and cut-off valves (part \#13). These features add to the safety and convenience of the system, but also increase the cost. If the filter will be used only when a pump is operating, and the pump is capable of delivering no more than 10 psi, these features may not be necessary. The source of water whether continually pressurized or pressurized only by an auxiliary pump, the range of pressures that the pump could deliver, the size of the irrigation project, and the relative supply of capital and labor will determine the usefulness of these options to a grower.

The plans allow connection to a 1-inch $(3.8-\mathrm{cm})$ flexible pipe for both the inlet to and the outlet from the barrel. Materials and parts throughout the filter can be substituted, depending on local availability. Connections to the cut-off valves may be either threaded (part \#20) or slip (part \#4), depending on the valve being used. Materials needed for the model shown here are given in Table 1.

Water delivery rates, and thus the acreage that can be irrigated by one filter, will be affected by the type and quantity of sand in the barrel, and by the delivery tubes in the barrel. In order to estimate the acreage that could be irrigated with such a filter, flow rates were measured through a fiber constructed according to the previous specifications with different types and amounts of sand. A water supply providing $39 \mathrm{gal} /$ rein (147.6 liters/rein) at $10 \mathrm{psi}(69 \mathrm{kpa})$ was connected to the filter without sand, with \#20 crushed sand, and with commercially available masonry sand. A description of the different-sized components of each sand is noted in Table 3. The flow measured from the filter with and without the two types of sand is noted in Table 4.

More flow restriction was caused by the delivery tubes in the filter than by the sand. The filter without sand restricted the flow by $8.7 \mathrm{gal} / \mathrm{rein}$ (32.9 liters/rein) relative to the unrestricted flow without the filter. If higher flow rates are needed, larger-diameter

Table 3. Size attributes of two types of sand used in the filter.

\begin{tabular}{llcr}
\hline & & \multicolumn{2}{c}{ Retained on screen (\%) } \\
\cline { 3 - 4 } Screen size & \multicolumn{1}{c}{ Sicve opening } & Masonry sand & $\# 20$ Sand \\
\hline 10 & 0.0787 inch $(2.0 \mathrm{~mm})$ & 1.0 & 0.0 \\
18 & 0.0394 inch $(1.0 \mathrm{~mm})$ & 1.8 & 0.0 \\
35 & 0.0197 inch $(500 \mu \mathrm{m})$ & 24.8 & 99.2 \\
60 & 0.0098 inch $(250 \mu \mathrm{m})$ & 54.6 & 0.6 \\
120 & 0.0049 inch $(125 \mu \mathrm{m})$ & 14.2 & 0.0 \\
230 & 0.0025 inch $(63 \mu \mathrm{m})$ & 3.0 & 0.0 \\
$>230$ & $<0.0025$ inch $(<63 \mu \mathrm{m})$ & 0.4 & 0.0 \\
\hline
\end{tabular}

Table 4. Water flow through a barrel filter with 0, 100, 150, or $200 \mathrm{lb}(0$, $45.4,68.1$, or $90.8 \mathrm{~kg}$ ) of two types of sand. Flow prior to connection to the filter was 39gal/min (147.6 liters/rein) at 10psi $(69 \mathrm{kPa})$.

\begin{tabular}{|c|c|c|c|c|c|}
\hline \multicolumn{2}{|c|}{ Sand } & \multicolumn{4}{|c|}{ Flow rate } \\
\hline (lb) & $\overline{(\mathrm{kg})}$ & (gal/imin)) & (liters/fmiin)) & (gal/min) & liters//riin) \\
\hline & & \multicolumn{2}{|c|}{ Masonry sand } & \multicolumn{2}{|c|}{ \#20 Crushed sand } \\
\hline 0 & 0 & 30.3 & 114.7 & 30.3 & 114.7 \\
\hline 100 & 45.4 & 30.3 & 114.7 & 29.7 & 112.4 \\
\hline 150 & 68.1 & 29.0 & 109.7 & 29.0 & 109.7 \\
\hline 200 & 90.8 & 28.0 & 106.0 & 28.0 & 106.0 \\
\hline
\end{tabular}


Table 5. Area irrigated with one filter and a 39-gal/min flow rate, using drip line with emitters on 12-inch $(30.5-\mathrm{cm})$ centers, delivering 0.2 gal/rnin per $100 \mathrm{ft}$ of row at 8 psi $(2.5$ liters/min per $100 \mathrm{~m}$ at $55 \mathrm{kPa}$ ).

\begin{tabular}{|c|c|c|c|c|c|c|c|}
\hline \multicolumn{2}{|c|}{ Row spacing } & \multicolumn{2}{|c|}{ Drip lime needed } & \multicolumn{2}{|c|}{ Water needed } & \multicolumn{2}{|c|}{ Area irrigated } \\
\hline (inch) & $\overline{(\mathrm{m})}$ & (ft/acre) & (m/ha) & (gal/rein) & (liters/rein) & (acre) & (ha) \\
\hline 30 & 0.76 & 17,424 & 13,157 & 35 & 132 & 1.1 & 2.7 \\
\hline 36 & 0.91 & 14,520 & 10,989 & 29 & 110 & 1.3 & 3.2 \\
\hline 48 & 1.22 & 10,890 & 8,197 & 22 & 83 & 1.8 & 4.4 \\
\hline 60 & 1.52 & 8,712 & 6,579 & 17 & 64 & 2.3 & 5.7 \\
\hline 72 & 1.83 & 7,260 & 5,464 & 15 & 57 & 2.6 & 6.4 \\
\hline
\end{tabular}

pipe with larger slots in the delivery tubes should increase the flow rate. The addition of different types and amounts of sand decreased the flow an additional 0 to $2.3 \mathrm{gal} / \mathrm{rein}(8.7 \mathrm{li}$ ters/min) (Table 4). Thus, the exact quantity of sand did not affect drastically the rate of water flow.

The flow of water needed to irrigate an acre of land will vary with the type of drip line, row spacing, and distance between emitters. One manufacturer produces several drip lines that range from 0.17 to $0.67 \mathrm{gal} / \mathrm{rein}$ per $100 \mathrm{ft}$ (2.1 to 8.3 liters/rein per 100 $\mathrm{m})$ of line in discharge, which would require from 25 to $97 \mathrm{gal} /$ rein per acre at 8 psi (234 to 906 liters/rein per ha at $55 \mathrm{kPa})$ for a 36 -inch $(0.9-\mathrm{m})$ row spacing. The range depends on emitter size and spacing (T-Systems Corp.). Typical areas that could be irrigated for crops that have different row spacings are shown in Table 5. For Table 5, the drip line used had emitters on 12-inch $(30.5 \mathrm{~cm})$ centers and delivered $0.2 \mathrm{gal} / \mathrm{rein}$ per $100 \mathrm{ft}$ of row length at 8 psi (2.5 liters/rein per 100 $\mathrm{m}$ at $55 \mathrm{kPa}$ ).

To determine the ability of the two types of sand to remove solid particles from the water, samples of surface pond water were collected both before and after filtration through each type of sand. The samples were oven-dried and the residues were weighed. Based on the time required for sediment settling (Cook and Pace, 1982), the water was determined to contain primarily clay particles, which, by the USDA and the International Society of Soil Science definitions, are $<0.002 \mathrm{~mm}$ in diameter (Brady, 1984). Sand filters should be designed to remove particles $>70 \mathrm{pm}$, which are at least 35 times greater than individual clay particles. Thus, they would not be required to remove individual clay particles, but clay particle aggregates could be large enough to clog emitters. Analysis of the water before and after filtra- tion showed that 0.26 gal (1 liter) of the unfiltered water contained $0.28 \mathrm{~g}$ of sediments. The same amount of water passing through $100 \mathrm{lb}$ (45.4 $\mathrm{kg}$ ) each of the masonry sand and the \#20 crushed sand contained 0.06 and $0.03 \mathrm{~g}$ of sediments, respectively. Because the filter removed between $79 \%$ and $89 \%$ of the clay particles, it would be expected to remove even more of the larger particles that could clog drip irrigation lines.

Both types of sand used in this study removed most of the clay from the water. Depending on local conditions and needs, a grower might be able to substitute a common, low-cost sand for the \#20 crushed sand, assuming that the sand used is not sized in such a way that compaction occurs. The quality of common sand available locally and the size of sediment particles in the water will determine the type of sand to be purchased.

The effective filtering agent in this system is sand. As such, it is similar to other commercially available filtration systems. This system would not be expected to out-perform other systems using similar sand. The system described here also lacks many of the automated controls that are available on commercial models, and close attention may be required to ensure that back-flushing is performed when needed. However, the performance of this filter in association with its low cost should make it useful for many growers.

\section{Literature Cited}

Brady, N. C. 1984. The nature and properties of soils. Macmillan, New York. p. 37.

Cook, M.G. and Pace, G.M. 1982. Concepts in soil science. North Carolina State Univ. Raleigh. pp. 75-79.

T-Systems Corporation. n.d. T-tape manual. T-Systems Corp., San Diego, Calif. 